PLANT PHYSIOLOGY

\title{
Heterotrimeric G Proteins: Key Players in Plant Growth and Stress Responses
}

\author{
Binny Sharma ${ }^{1}$, Padmanabh Dwivedi ${ }^{1 "}$ and Asha Kumari ${ }^{2}$ \\ ${ }^{1}$ Department of Plant Physiology, Institute of Agricultural Sciences, Banaras Hindu University, Varanasi, India \\ ${ }^{2}$ Crop Improvement Division, ICAR-Vivekananda Parvatiya Krishi Anusandhan Sansthan, Almora, Uttarakhand, India \\ "Corresponding author: pdwivedi25@rediffmail.com (ORCID ID: 0000-0003-2350-0828)
}

Paper No. 873

Received: 23-08-2020

Revised: 24-11-2020

Accepted: 08-12-2020

\begin{abstract}
Heterotrimeric $G$ proteins are large membrane-associated $G$ proteins with subunits $(G \alpha),(G \beta)$, and $(G \gamma)$ present in the plasma membrane in eukaryotes. They are signal transducers that play an important role in signaling pathways in various living organisms. In the inactive stage, $\mathrm{G} \alpha$ contains guanosine diphosphate and forms the heterotrimeric complex with $\mathrm{G} \beta \gamma$ dimer which is activated by nucleotide exchange on $\mathrm{G} \alpha$ for guanosine triphosphate (GTP), GTP bound G $\alpha$ dissociates from G $\beta \gamma$ dimer and modulates the effector for downstream signaling. Regulator of G protein signaling (RGS) protein is a regulatory point of $\mathrm{G}$ protein activation and stimulates rate-limiting GTPase activity of G $\alpha$ subunit. G-protein research in plants is getting a lot of attention recently due to the emerging roles in modulating abiotic and biotic stress responses. An increase in the frequency of extreme weather and climate change has accelerated the adverse effect from plant stresses which are detrimental for plant growth. G-proteins plays important role in various functions that enhances plant growth and development, regulation of hormones, signals, stresses and plant defense responses. Furthermore, future research should be directed towards the discovery of novel components and their signaling mechanisms.

\section{Highlights}

( Guanine nucleotide binding proteins (G- proteins) are cytosolic proteins that are present in trimeric complex with $\alpha, \beta$ \& $\gamma$ subunits in plants.

0 They act as signal transducers that regulate multiple signaling pathways in eukaryotes.

( Heterotrimeric G- proteins play vital role in plant growth and development in many plant species.

( Besides roles in plant growth, they are also important for mitigation of abiotic (salt, drought, ozone, temperature) stresses and plant defense responses by inducing different mechanisms.
\end{abstract}

Keywords: Abiotic stress, G proteins, RGS protein, GTPase, Biotic stress.

The potential climatic abnormalities and changing environmental conditions enable plants to experience numerous abiotic and biotic stresses during their growth and development. Abiotic stresses are drought, elevated temperature, saline conditions, cold, high ultraviolet (UV) radiation, nutrient stress and accumulation of heavy metals in the soil, etc which have been shown to be detrimental for crop production at different developmental stages, also influencing the occurrence of biotic stresses like spread of pathogen, insects-pests, weeds, etc and prove to be potential threat in the future. They not only influences plant morphological responses but also affect crop defense system as well (Scherm and Coakley 2003). Plants, though, have developed several mechanisms to cope with these environmental abnormalities. Despite morphological adaptations, they have also intricated several molecular pathways and mechanisms to deal with these stress responses which include signal perception by receptors, signaling via molecules

How to cite this article: Sharma, B., Dwivedi, P. and Kumari, A. 2020 Heterotrimeric G Proteins: Key Players in Plant Growth and Stress Responses. IJAEB, 13(4): 497-509.

Source of Support: None; Conflict of Interest: None (क) 
and proteins, gene expression (Pandey et al. 2015). Extensive study in the areas of stress tolerance mechanisms has come across in integrating the potential functions of G-proteins in stress biology. This review aims at unraveling the different fundamental roles of G-protein science in controlling plant morphological responses and different adaptations towards stress responses. Heterotrimeric $\mathrm{G}$ proteins refer to as guanine nucleotide binding proteins present at plasma membrane of eukaryotic cells. These are cytosolic protein categorized as large membrane associated $G$ proteins consisting of 3 subunits namely $G \alpha, G \beta$ and $G \gamma$ forming a heterotrimeric complex. In early 1970s, G proteins were recognized as a signal transducer which links hormone receptor and adenylyl cyclase in mammals (Urano et al. 2013). The Ross, Gilman and Rodbell in late 1970s showed that GTP binding proteins (G- proteins) are involved in production of cAMP by action of epinephrine (Tuteja et al. 2008). The first $\alpha$ - subunit of $\mathrm{G}$ protein in plants was cloned from Arabidopsis (AtGPA1) in 1990 (Urano et al. 2013). Later in 2007, the self replicating property of G protein was discovered.

Plant's genome contains different group of $G$ proteins unlike animals. A typical angiospermic plant contains two kinds of $\mathrm{G} \alpha$ viz., a canonical $\mathrm{G} \alpha$ and non-canonical extra-large $G \alpha$, one type of $G \beta$ and three forms of $G \gamma$ i.e., Type A, Type B and Type C G $\gamma$ subunits ( $\mathrm{Wu}$ et al. 2018). Human genome encompasses $23 \mathrm{G} \alpha, 5 \mathrm{G} \beta$ and $12 \mathrm{G} \gamma$ subunits whereas the Arabidopsis genome comprises of one canonical G $\alpha$ (GPA1), 3 non-canonical G $\alpha$ like extralarge $G$ protein (XLG1, XLG2 and XLG3), one $G \beta$ (AGB1) and 3 G $\gamma$ subunits i.e., AGG1, AGG2 and AGG3. G- proteins have been extensively studied in several crop species like dicots (Arabidopsis thaliana, soybean, pea) monocots (maize, rice), gymnosperm (Pinus taeda) and in bryophytes (Physcomitrella patens) which possess two copies of $G \beta$ and $G \gamma$ genes but no canonical $\mathrm{G} \alpha$. The rice genome, on the other hand, consists of one G $\alpha$ (RGA1), G $\beta$ (RGB1) and 3 G $\gamma$ (RGG1, RGG2 and RGG3) subunits, respectively.

\section{Functions of Heterotrimeric G- proteins in Plants}

Several researches over past few decades have reported that heterotrimeric G-proteins play important functions in various functions that enhance plant growth and development, regulation of hormones, signals, stresses, etc. In humans, they are basically an important signal transducing agents in the cells. They are involved in deregulation of GPCR activity and downstream circuits were reported in many diseases like schizophrenia, Alzheimer, cancer, obesity, hypertension and diabetes (Graneir 2012; Hayre 2013; Thathiah, 2011). GPCR signaling is major area of cell biology and therapeutics and its functioning has been most widely studied in protein function (Kamato 2015). In animals, they also transmit extracellular signals like hormones, neurotransmitters, light, taste, etc into intracellular signaling components. Physiological and genetic analysis reveals the functions of heterotrimeric $G$ proteins in various plant physiological and developmental processes. The study of G-proteins in Arabidopsis showed that it regulates several functions like germination of the seed (Ullah et al. 2002), root cell division (Chen et al. 2006), modulates cell proliferation (Chen et al. 2003), regulates nitrate, cell wall, immunity and light responses (Chakraborty et al. 2019), modulates responses to plant hormones (Mishra et al. 2006; Pandey et al. 2004). The heterotrimeric G-proteins have been extensively studied in other plant species like rice, soybean, maize, pea, Camelina etc. In rice, heterotrimeric G- proteins regulate nitrogen use efficiency (Sun et al. 2014), G $\gamma$ proteins (DEP1, GGC2) determines grain size in complex with $G \beta$ subunit (Sun et al. 2018). In maize, it controls shoot meristem development, immune responses and enhances agronomic traits (Wu et al. 2019; Wu et al. 2018), controls cell expansion in Camelina sativa (Choudhary et al. 2019), regulates ABA and auxin signaling in tomato (Subramaniam et al. 2016), nodule formation in soybean (Choudhary et al. 2015), elongation of culm and grain size in barley (Wendt et al. 2016). XLG protein, a functional and biochemical form of canonical $\mathrm{G} \alpha$ controls the development, sporophyte formation and life cycle completion in $P$. patens. Mudgil et al. (2016) reported that G- proteins play vital role in mediating the glucose effect on root system architecture in Arabidopsis through auxin patterning and transcriptional control. AGB1 acts as sensor component of glucose or carbon nutrient status in roots and modulates root growth. FerreroSerrano et al. (2017) studied photoavoidance and photoprotection of a dwarf rice mutant with erect 
leaves (d1) where RGA1 gene encoding $\mathrm{G} \alpha$ subunit of G-protein is non-functional. Leaves of d1 has lower leaf and high photochemical reflectance index compared to wild type (WT) indicating increased photoavoidance and more efficient light harvesting. G-proteins have important role in development of shoot apical meristem (SAM) in maize. Thus, most of our knowledge about G- proteins from plants comes from studies which depicts that they control various physiological and developmental processes in plants (Table 1). Although the diverse role of HGPs has been identified in plants, the detail mechanism of their action and signaling pathway are needed to be explored.

Table 1: Physiological functions of Heterotrimeric G- proteins in plant species

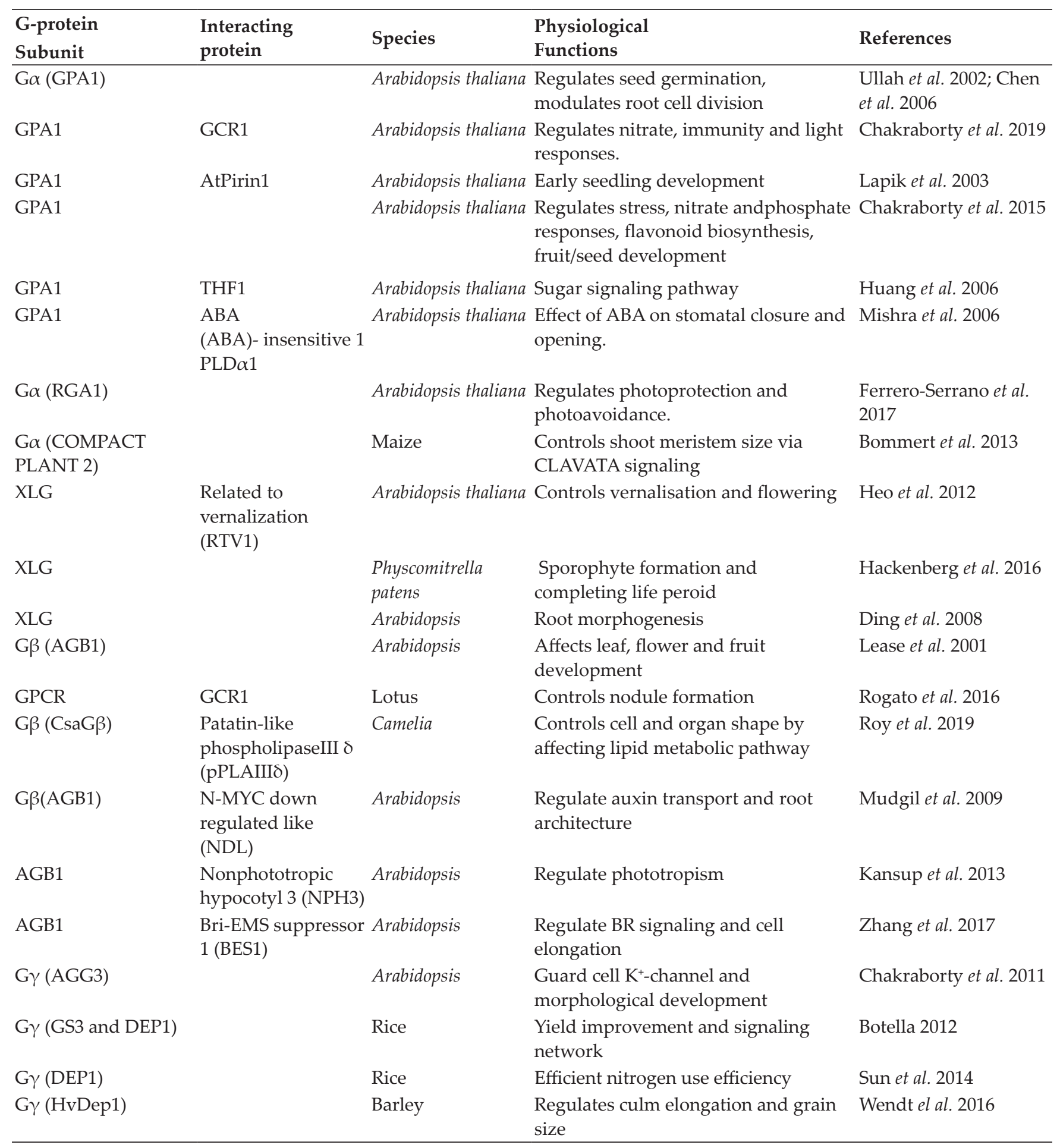




\section{Heterotrimeric $\mathrm{G}$ protein signaling}

The heterotrimeric $\mathrm{G}$ proteins complex are located in plasma membrane which acts as molecular switches to regulate multiple signaling pathway in eukaryotes. The core $G$ protein component comprises of $G \alpha, G \beta$ and $G \gamma$ subunits. The classical model of HGPs signaling describes that this $G$ protein complex swaps between active and inactive stages depending on nucleotide bound form of $\mathrm{G} \alpha$. In inactive state, $\mathrm{G} \alpha$ which is bound to GDP also remains associated with $G \beta \gamma$ dimer. Resumption of $G$ protein signaling is mediated by its activation by ligand-binding thus causes change in conformation of GPCRs. The activated GPCR functions as guanine nucleotide exchange factor (GEF) which catalyzes exchange of GDP to GTP situated on G $\alpha$ protein resulting in dissociation of $\mathrm{G} \alpha$ subunit with $\mathrm{G} \beta \gamma$ dimer. GTP- G $\alpha$ monomer and G $\beta \gamma$ dimer interacts with downstream effectors state of signaling. Activation and deactivation of G-protein requires synchronization for effective and continuous signaling (Ross et al. 2008). Since the inherent rate of GTP hydrolysis by G $\alpha$ is slower than GDP/ GTP exchange rate, the proteins are required that can accelerate GTPase activity of G $\alpha$. The GAP proteins thus enhance the rate of GTP hydrolysis by interacting with $\mathrm{G} \alpha$ proteins and facilitate effective deactivation and continuation of cycle (Pandey et al. 2018). GPCRs, on the other hand, are important gateway for signal transduction induced by ligand binding. They are seven transmembrane $\alpha$ helices with extracellular $\mathrm{N}$ - terminal tail and intracellular loops with $\mathrm{C}$-terminus involved in $\mathrm{G}$ protein receptor regulation (Stewart et al. 2015). GPCR binding to $G \alpha$ subunits are specific and allows ligand specific modulation of downstream signaling in cells. The RGS proteins are most well known GAPs of G $\alpha$ proteins (Stewart el al. 2015; Siderovoski et al. 2005; Ross et al. 2008). The human genome consists of $23 \mathrm{G} \alpha, 5 \mathrm{G} \beta, 12 \mathrm{G} \gamma, 37$ RGS and about 1000 GPCRs. Compared to this, the G-proteins are extremely limited in plants i.e., 1 canonical $G \alpha, 1 G \beta$, 2 canonical $G \gamma$, 1unique RGS and no GEF activity possessing GPCR, even though additional noncanonical plant specific proteins exist and function together with G- protein cycle (Stateczny et al. 2016; Urano et al. 2014; Colaneri et al. 2014). Several studies have been made during past few decades to underline the importance of G- protein signaling in plants. They play pivotal roles in regulation of multiple plant growth and developmental processes as roles of $\mathrm{G}$ protein subunits have been demonstrated in controlling seed germination, seedling development, ion channel regulation, stomatal development. G-proteins have immense role in hormone signaling, sugar sensing, light signaling, ROS mediated signaling in many plant species. Unlike animals, in plants the exchange guanine nucleotide in $\mathrm{G}$ alpha is mediated in absence of GPCR and the intrinsic hydrolysis rate is slow. In animals, G proteins bind GDP and removal of this nucleotide allow GTP to bind required a receptor having GEF activity, whereas in plants, G proteins are self- activating, spontaneously release GDP and binds GTP in vitro (Urano et al. 2014). Plants possess canonical and unique $G$ protein components. Their basic biochemistry is, moreover alike from that of metazoans G- proteins, where the classic GPCRs are required for exchange of GTP from GDP for G $\alpha$ protein activation which is intriguingly missing from plant genomes. Hence, mechanism of G- protein action in plants is slightly dissimilar from metazoan systems.

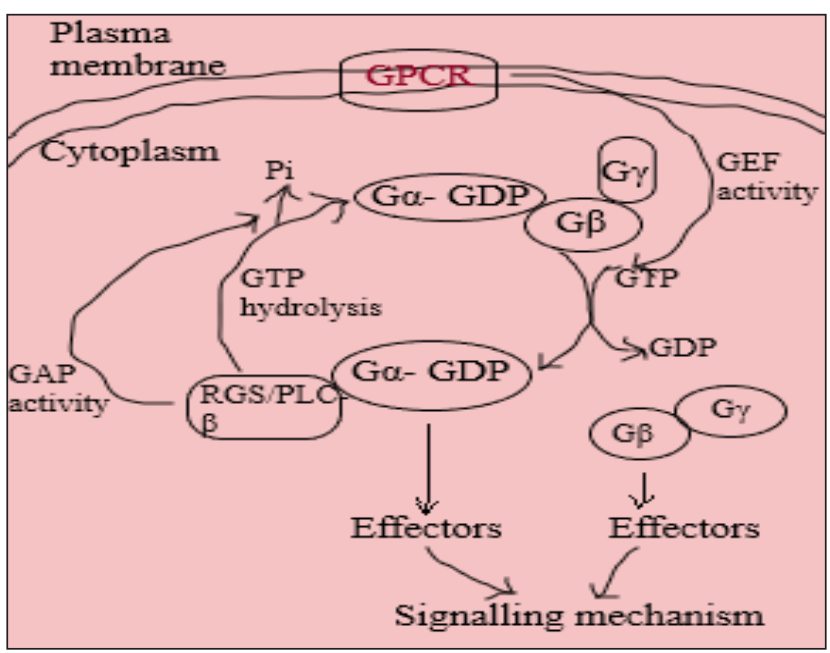

Fig. 1: G protein signaling mechanism (Source: Pandey, 2019).

\section{Heterotrimeric G- protein signaling mechanism}

Heterotrimeric G- proteins consist of $\mathrm{G} \alpha, \mathrm{G} \beta$ and $\mathrm{G} \gamma$ subunits. GPCRs and GAPs mediate GDP to GTP exchange reactions of $G \alpha$ and slow inherent GTPase activity of $\mathrm{G} \alpha$ proteins, respectively. In active state, $G$ proteins interact with downstream effectors to transduce signal. 


\section{Activation of G-proteins in plant system}

$\mathrm{G}$ protein cycle continuum is influenced by many factors which together regulate its rate and continuity. The activation cycle depends on GDP/ GTP exchange, GDP dissociation rate from $\mathrm{G} \alpha$ and rate at which GTP binds on G $\alpha$ protein, whereas deactivation depends on GTP hydrolysis by G $\alpha$ \& several factors that accelerates the processes (Pandey and Vijaykumar 2018). Thus, both conserved and novel signaling mechanism operate during plant G- protein signaling. In metazoan system, activation of G- proteins occurs due to GEF activity of GPCRs which is missing in plant system. Although they possess several proteins having 7 transmembrane features similar to mammalian GPCR which interacts with $\mathrm{G} \alpha$ proteins in plants. There are several underlying possible mechanisms for the activation of $G$ proteins signaling pathway in plants. Although the canonical, GEF activity possessing GPCRs could possibly be present in plants but has not been identified yet. Many proteins present in plants interact with $\mathrm{G} \alpha$ subunit. GCR1, a well characterized GPCR like Arabidopsis protein has significant genetic evidence that it plays fundamental in pathways regulated by Arabidopsis G $\alpha$ protein, GPA1 (Apone et al. 2003; Pandey and Asmann 2004; Pandey et al. 2016; Warpeha et al. 2006; Chakraborty et al. 2015a, b). The plant Gproteins are self activating as discussed earlier hence do not require GPCR (Urano et al. 2012a, b). This can be hypothesized from a fact that under in vitro condition, Arabidopsis GPA1 possesses higher rate of GTP binding and displays slow GTPase activity. In case of in vivo, the cells contain increased concentration of GTP, a G $\alpha$ protein will substantially remain in GTP bound conformation. This implies that $G \alpha$ remains active unless it is deactivated which opposes the existing established paradigm (Pandey et al. 2018). One another possibility exists which confer that RLKs are involved in activation of $\mathrm{G} \alpha$ proteins that further interact with Gprotein signaling pathway in plants. RLKs have been involved in defense related signaling but involvement of the same during plant development has also been witnessed. RLKs regulate the activity of SAM development in maize. Genetic screening in maize revealed CT2 is an interactor of CLV2 as CLV and WUSCHEL signaling pathways controlled SAM development in plants. Knocking down either CT2 or FEA2 increased SAM size. RLKs also regulate nodule formation in maize. Genetic analysis demonstrated that $G \alpha$ proteins negatively regulate while $G \beta \gamma$ or RGS protein positively regulates the nodule formation. Nodulation in soybean is stimulated by perception of rhizobial nodulation factor (Nod factor) by Nod factor receptor 1 (NFR1) containing RLKs. Phosphorylation of RGS proteins promote GAP activity and allows nodule formation by maintaining inactive state of $\mathrm{G} \alpha$ protein (Pandey 2019).

\section{Deactivation mechanism of $G$ proteins}

$\mathrm{G}$ proteins deactivation mechanism is mediated by GTPase activity, GTP bound G $\alpha$ hydrolysis to bound GTP and thus regenerate GDP in inactive form, although the exact mechanism of activation and deactivation of plant $\mathrm{G} \alpha$ proteins are still to be determined. Since, the GTPase action of G $\alpha$ proteins in plants is relatively slow, several proteins with GAP activity are required to synchronise activation and deactivation mechanism. RGS protein is well established and recognized GAP in all organisms. In plants, RGS proteins discovery are characterized transmembrane domain linked to RGS domain. RGS protein acts together with $G \alpha$ protein which are functionally important for effective signaling via G- proteins. Along with RGS, PLD $\alpha 1$ in Arabidopsis also accelerates GTP- hydrolysis by G $\alpha$. The phenomenon by which phospholipases act as GAPs is well known in mammalian system where PLC $\beta$ isoforms act as GAPs and also as effectors of $\mathrm{G} \alpha$ proteins (Pandey et al. 2018; Ross 2008; Xu et al. 2015; Litosch et al. 2013, Ross 2011). Genetic and biochemical analysis confirmed that RGS1 and PLD $\alpha 1$ in Arabidopsis accelerates GTPase activity of Ga (Pandey 2017; Roy Choudhary et al. 2016; Hong et al. 2016; Zhao et al. 2013; Pandey, 2016). They interact among themselves and additionally with core $G$ proteins to form higher order protein complexes in vivo.

\section{G- proteins are key regulators of abiotic stress responses}

Heterotrimeric $G$ proteins regulate various physiological and developmental processes in plants, additionally influencing abiotic stress responses. Plants cope with several abiotic stresses by evolving numerous molecular mechanisms due 
to which plant sense stress signal followed by transduction and generation of response (Pandey et al. 2016).

\section{Salt Stress}

Salinity stress is one of the most important abiotic stresses which results when salts in arid and semiarid regions gets accumulated over long period. Salt stress causes ionic, osmotic and oxidative stress, not only controlling growth but also influences photosynthetic rate, turgor and enzymatic activity of plants. In Arabidopsis, AGB1 efficiently regulates salt tolerance by modulating transcription of genes related to biosynthesis of proline, oxidative stress and responses to ABA as AGB1 mutant (agb1-2) shows decreased survival rates, seed germination rates but increase in MDA concentration and concentration of $\mathrm{Na}^{+} / \mathrm{K}^{+}$than WT (wild type) with increase in $\mathrm{NaCl}$ concentration (Ma et al. 2015). Swain et al. (2017) studied the role of rice G- protein $\gamma$ subunit (RGG1) in salinity tolerance in rice. The signaling events facilitated by RGG1 conferred salinity tolerance by increasing gene expression of antioxidant enzymes. Gene encoding Salt Inducible Zing Finger 1\&2 (SZF1\& SZF2) is involved in XLG pathway for salt stress response (Liang et al. 2017). Liu et al. (2019) reported that overexpression of mulberry G- protein MaG $\beta$, MaGY1 \& MaGY2 in tobacco increased salt tolerance by modulating ROS detoxification. Under $\mathrm{NaCl}$ treatment, the agb12 mutant and rgs1-2 mutant of Arabidopsis have contrasting phenotype of small and large chlorotic leaves, respectively and this phenotype with loss of function mutations suggest that $G$ proteins promotes growth and attenuates senescence (Colaneri et al. 2014). It is well known fact that as salt concentration increases the water potential of soil lowers down which causes osmotic stress and limits uptake of water by plants. The knockout mutant of Arabidopsis agb1 shows hypersensitivity to salt and leaf blanching, which accumulates more $\mathrm{Na}^{+}$and less $\mathrm{K}^{+}$in both roots and shoots in hydroponically grown plants (Yu and Assmann 2015). Increase in salt concentration lowers the water potential of soil which causes osmotic stress and limits uptake of water by plants. $\mathrm{G} \alpha$ null mutations in rice and maize bestowed reduced senescence of leaves, degradation of chlorophyll pigments and cytoplasm electrolyte leakage under salt stress (Urano et al. 2014).

\section{Drought stress}

Drought stress being multidimensional, affects morpho-physiological, biochemical and molecular traits of plants. It substantially depletes leaf water potential, relative water content (RWC) and transpiration rate with increase in leaf temperature of plant (Farooq et al. 2009). The rice d1 mutant possess RGA1 gene and encodes GTP binding $\alpha$ subunit exhibits greater stomatal conductance, endured photosynthesis and increased resistance to drought stress than wild type (WT) ( FerreroSerrano et al. 2016). Genetic analysis showed that HGPs plays a vital role in stomatal opening. In Arabidopsis, GPA1 and AGB1 antagonistically regulates stomatal density as overexpression of constitutively active form of GPA QL increased stomatal density and, in contrast, the stomatal density enhanced in null mutant of G- protein $\beta$ subunit (AGB1) but decreased in transgenic lines overexpressing AGB1 (Zhang et al. 2008). Oxidative stress and ROS production increases during drought stress which results in cell damage and death. Over-expression of mulberry $\beta$ subunit in transgenic tobacco enhanced drought tolerance as transgenic tobacco possess increased proline content, decreased MDA and $\mathrm{H}_{2} \mathrm{O}_{2}$ content with less superoxide free radical accumulation (Liu et al. 2017). In rice, it is suggested that RGB1 (rice $\beta$ subunit) positively stimulates $\mathrm{ABA}$ responses and drought stress tolerance and qPE9 (rice $\gamma$ subunit) negatively stimulates ABA-mediated drought stress responses (Zhang et al. 2015). Heterotrimeric g protein signaling plays an important role in modulating stress responsive genes. The study in Arabidopsis genome suggests that overexpression of RGS1 stimulates drought tolerance and ABA biosynthetic enzymes (Chen et al. 2006). Phenotypic plasticity is a phenomenon in which one genotype displays different phenotype under different environmental conditions thus allowing plant to reimburse inevitable and inhospitable environment. $G$ proteins function as signaling input in crosstalk between hormonal and environmental conditions and hypothesized as plasticity gene. G protein mutant and WT shows significant difference in plasticities for a number of reproduction related traits. For instance, gpa1 or gcr1 possess enhanced plasticity for inflorescence height or fruit number while agb1 mutant consists of reduced plasticity 
for inflorescence height, seed number per fruit and total seed production under drought stress (Nilson and Asmann, 2010). Over-expression of AGG3 in transgenic Camelina shows enhanced vegetative and reproductive growth, increased photosynthetic efficiency, increased seed size along with higher oil yield per plant under drought stress (Roy Choudhary et al. 2014).

\section{Temperature stress}

The drastic change in temperature over recent decades induced high or low temperature. High temperature stress often attributed as rise in temperature past threshold level for a period of time which causes irreversible damage to plant growth and development (Wahid et al. 2007) whereas low temperature or cold stress is induced by exposure to reduced temperature usually below $0-15^{\circ} \mathrm{C}$. The role of G- proteins in temperature stress are yet to be explored as limited studies have been made under temperature fluctuations. Increased temperature sensing in Arabidopsis requires Phytochrome interacting factor 4 (PIF4) - transcription factor and changes in H2A.Z chromatin status (Kumar et al. 2012). Heat stress response is mediated by multiple pathway and regulatory network. Heat induced $\mathrm{Ca}^{2+}$ and ROS signaling plays a vital role in activation of HSFA1 to increase thermotolerance in plants (Mittler et al. 2012). HSFA1 is a master regulator of heat stress responses which initiates the transcription cascade of HSPs and other genes and also induces their activity under different stresses like salt, osmotic and oxidative stress to confer tolerance (Liu et al. 2011). Bai et al. (2018) reported that over-expression of CsGG3.2 (G $\gamma$ subunit) in transgenic plant exhibits chilling tolerance in cucumber with increased expression of CBF genes. Overexpression of KE1 gene (positive regulator of CBF3 gene) enhances chilling tolerance in transgenic Cucumis sativus L. Transgenic plant accumulated more soluble sugar and proline and showed increased activity of antioxidant enzyme with less electrolyte leakage than WT under cold stress (Liu et al. 2011). Overexpression of Pisum sativum G $\alpha$ and $G \beta$ showed thermo tolerance in transgenic tobacco $\left(\mathrm{T}_{0}\right.$ and $\left.\mathrm{T}_{1}\right)$ plants (Mishra et al. 2007). The agg 2 mutant of Arabidopsis when grown at higher temperature $\left(29^{\circ} \mathrm{C}\right)$ exhibits earlier flowering than WT (Thung et al. 2013). Wu et al. (2012) reported that plants exhibiting cold regulated gene CbCOR15b expressed in leaves, stems and roots possess greater cold tolerance than control. The QTL protein COLD1 interacts with RGA1 thereby stimulating GTPase activity to activate $\mathrm{Ca}^{2+}$ channels in response to chilling stress in rice (Ma et al. 2015b).

\section{Ozone stress}

Ozone being a secondary pollutant affects the plants at physiological and molecular level. Ozone enters the plant through stomata and breakdown in apoplast to produce ROS (Ludwikow and Sadowski 2008), thus induces oxidative stress and PCD. Long term exposure to ozone causes chlorosis and necrosis, reduced photosynthesis and decreased yield (Wu et al. 2018). Genetic evidence reveals that membrane associated GTP proteins play a crucial role in signal transduction by activation of target proteins and transduce extracellular signals to intracellular receptors (Booker et al. 2004).

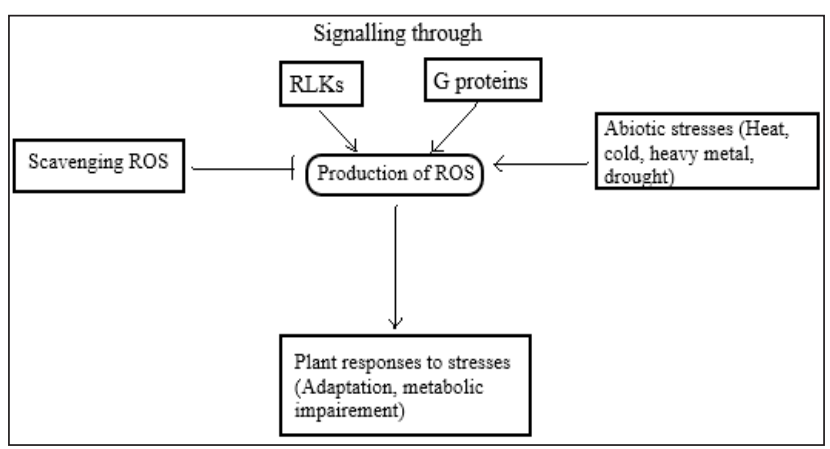

Fig. 2: G protein signaling in abiotic stress (Source: Lohani et al. 2020).

HGPs signaling also controls stress associated physiological responses. In Arabidopsis, epinasty was observed in WT instead of gpa1 mutant when treated with ozone $\left(\mathrm{O}_{3}\right)$. gpa1 mutant showed decreased leaf chlorophyll content and leaf mass per unit leaf area in response to $\mathrm{O}_{3}$. ROS production by $\mathrm{O}_{3}$ is facilitated in early and late times. Atrboh $D$ and Atrboh $F$ are cell membrane associated NADPH oxidases which triggers ROS production in initial time while the late ROS signal is described by tissue damage associated component of oxidative burst required only $G \alpha$ protein. $G$ protein signaling plays an important role in activating intracellular sources of ROS that contribute to first component of triphasic stress mediated oxidative burst in Arabidopsis (Joo 2005). Booker et al. (2015) studied the potential response mechanism of G-proteins to 
Table 2: Function of Heterotrimeric G protein in different abiotic stresses

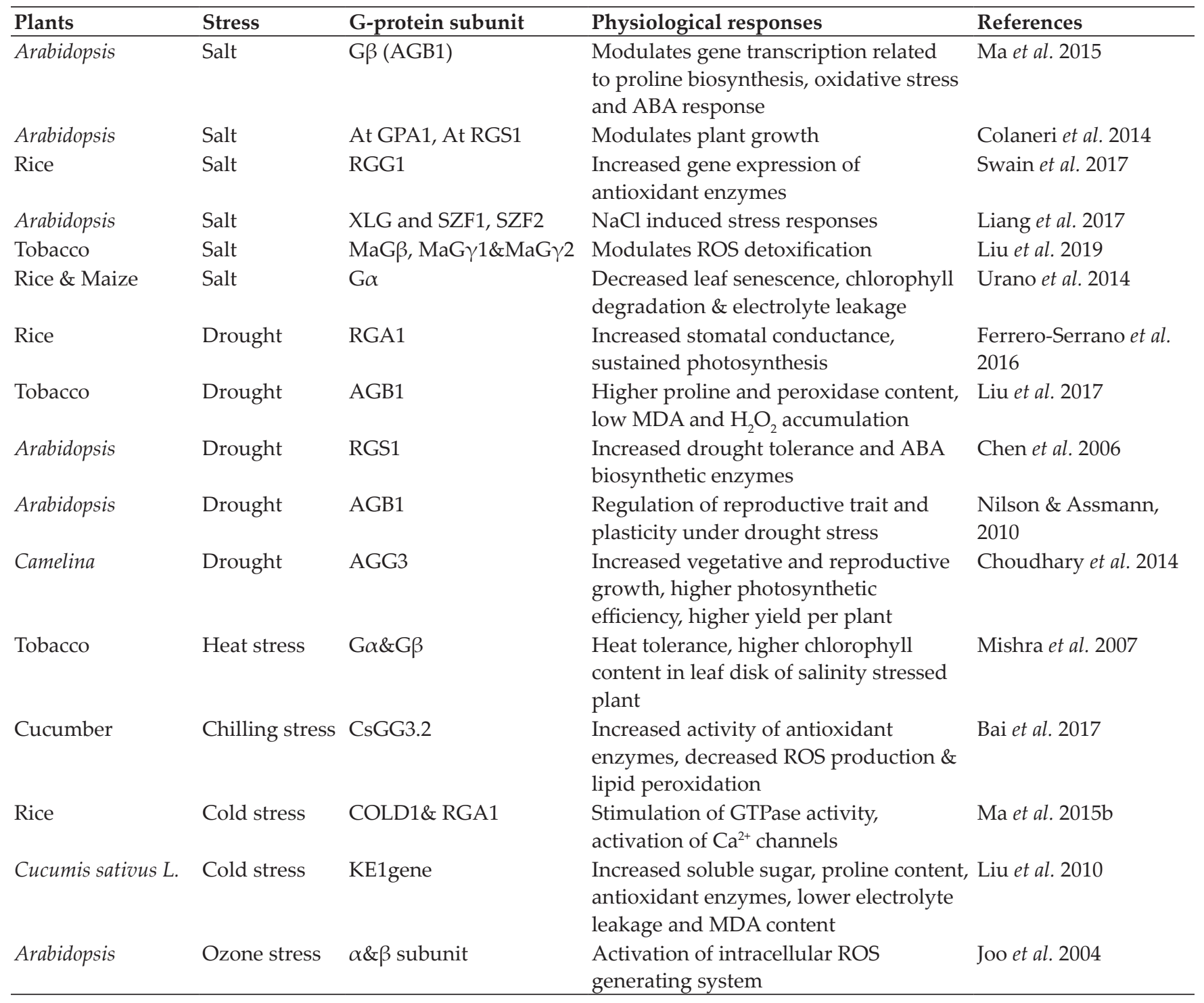

$\mathrm{O}_{3}$ by comparison between Arabidopsis null mutants of $\alpha$ and $\beta$ subunits (gpa 1-4, agb 1-2 and gpa 1-4/ agb 1-2) and WT. Transcript levels of GPA1, AGB1 and RGB1 genes were induced by $\mathrm{O}_{3}$. They further also reported that silencing of $\alpha$ and $\beta$ G-protein genes resulted in alteration of many processes associated with $\mathrm{O}_{3}$ injury, including ROS signaling genes, increase in leaf tissue ion leakage with reduced net photosynthesis. Many responses to $\mathrm{O}_{3}$ stress at physiological level were not necessarily influenced by $\alpha$ and $\beta$ G-protein (Booker et al. 2012).

\section{Role of $\mathrm{G}$ proteins in plant defense responses}

Heterotrimeric $G$ proteins are particularly involved in plant defense responses. They are involved in various facets of plant disease resistance.
Overexpression of $\mathrm{G} \alpha$ and $\mathrm{G} \beta$ subunit results in decreased bacterial multiplication of non-host pathogen $P$. syringae pv. tabaci while overexpression of $G \beta$ and not $G \alpha$ results in reduced bacterial growth of host pathogen P. syringae pv. Maculicola compared to wild type along with altered stomatal aperture by bacterial pathogen in $\mathrm{G} \alpha$ and $\mathrm{G} \beta$ mutants, not in single or double mutants (Lee et al. 2013). AGG1 and AGG2 proteins have redundant functions in controlling Arabidopsis immune response to necrotrophic fungus $P$. cucumerina indicting that susceptibility of agg1-1 agg1-2 double mutant to this pathogen is similar to that of agb1 plant but higher than agg1-1 agg 2-1 single mutants (Delgado- Cerezo et al. 2012). In contrast, Trusov et al. (2006) reported that AGG1 has specific role in 
Table 3: Function of Heterotrimeric G protein in different biotic stresses

\begin{tabular}{|c|c|c|c|}
\hline Mutant & Species & G-protein Subunit & Biotic stress response \\
\hline$x \lg 2$ & Arabidopsis & XLG 2\&XLG 3 & Enhanced susceptibility to P. synringae (Zhu et al. 2009) \\
\hline gpa1 & Arabidopsis & $\mathrm{G} \alpha$ & Reduction in stomatal density (Zhang et al. 2008) \\
\hline agb1 & Arabidopsis & $\mathrm{G} \beta$ & $\begin{array}{l}\text { Enhanced susceptibility to pathogen A. brassicola, B. cinerea, } \\
\text { F. oxysporum E P. cucurmerina (Llorente et al. 2005), Reduced } \\
\text { elicitor induced ROS production, increased susceptibility to } \\
\text { P.s.t DC } 3000 \text { E P. syringae pv. Maculicola (Torres et al. 2013), } \\
\text { restricted constitutive cell death \& defense responses in bir } \\
\text { 1-1, reduced resistance to non-pathogenic bacteria P.s.t DC } \\
3000 \text { hrcC (Liu et al. 2013). }\end{array}$ \\
\hline agg1 agg2 & Arabidopsis & $\mathrm{G} \gamma$ & $\begin{array}{l}\text { Impaired elicitor induced to P. syringae pv. tomato DC3000, } \\
\text { reduced MPK } 4 \text { activation by flg22, suppression of constitutive } \\
\text { cell death \& defense reponses in bir1-1 (Liu et al. 2013), } \\
\text { increased susceptibility to P.S.M \& P. synringae pv. Tabaci } \\
\text { (Lee et al. 2013), increased susceptibility to necrotrophic } \\
\text { fungi P. cucumerina, F. oxysporum, B. cinerea (Trusov et al. 2006; } \\
\text { Trusov et al. 2009; Trusov et al. 2007). }\end{array}$ \\
\hline d1 & Oryza sativa & $\mathrm{G} \alpha$ & $\begin{array}{l}\text { Decreased defense reponse to avirulent strains of X. oryzae } \\
\text { pv. oryzae \& M. grisea (Komatsu et al. 2004), decreased } \\
\text { hypersensitive response to avirulent strains of M. oryzae } \\
\text { (Suharsono et al. 2002). }\end{array}$ \\
\hline Silencing of $\mathrm{G} \alpha$ & Nicotiana & $\mathrm{G} \alpha$ & Impaired elicitor, activated stomatal closure, decreased NO \\
\hline Silencing of G $\beta 1$ \& G $\beta 2$ & benthamiana & $\mathrm{G} \beta$ & $\begin{array}{l}\text { production in guard cells in response to elicitor, attenuation } \\
\text { of elicitor induced } \mathrm{H}_{2} \mathrm{O}_{2} \text { accumulation, suppress harpin } \\
\text { induced cell death (Zhang et al. 2012) }\end{array}$ \\
\hline
\end{tabular}

the mediating Arabidopsis resistance to necrotrophic fungus $A$. brassicola. Heterotrimeric G-proteins plays an important role in plant defense by mediating ROS production by NADPH oxidases (VeraEstrella et al. 1994). G- proteins influences cell wall components, ROS production and also interacts with JA and MAP kinase signaling network component as plant response to pathogens (Torres et al. 2013). Transcriptome analysis revealed that extra- large G protein (XLG 2 and XLG 3) were greatly incited by infection with bacterial pathogen $P$. syringae as loss of function mutation of $x \lg 2$ increased susceptibility to the same in Arabidopsis (Zhu et al. 2009). Studies on the G-proteins provide an evidence that they are involved in resistance to wide range of pathogens. Arabidopsis genome consists of 3 non- canonical G $\alpha$ i.e. XLG1, XLG 2 and XLG 3. The Arabidopsis triple mutant $x \lg 1, x \lg 2, x \lg 3$ and quadruple mutant gpa1xlg1 xlg2 xlg3 showed impaired resistance and no additive effect in susceptibility between triple and quadruple mutant showing that GPA1 does not play role in disease resistance (Urano et al. 2016a). In Arabidopsis, G $\beta \gamma$ dimer associates with XLG to confer plant immunity as Arabidopsis mutant lacking XLG, G $\beta$ and $G \gamma$ shows reduced pathogen defense, development and production of ROS as well (Maruta et al. 2015). Study in rice reveals that rice $\mathrm{d} 1$ mutant which lacks RGA1 possesses decreased defense responses to avirulent strains of X. oryzae pv. Oryzae and M. grisea (Komatsu et al. 2004). Arabidopsis mutant deficient in AGB1 (G $\beta$ subunit) are highly susceptible to pathogens viz., $A$. brassicola, B. cinerea, F.oxysporum and P. cucumerina (Llorente et al. 2005; Trusov et al. 2009), agb1 mutant shows hindered induction of MeJA induced PR genes, PDF12, OPR3 and PAD1 (Trusov et al. 2009), whereas SA dependent PR1 expression was enhanced after P. cucumerina infection (Llorente et al. 2005). Studies on G- protein also reveals that they are actively involved in elicitor induced hypersensitive respone (HR) in plants by VIGS induced silencing of $\mathrm{G} \alpha, \mathrm{G} \beta$ and $\mathrm{G} \beta 1$ subunit of $N$. benthamiana and $G$ protein complex. The treatment of silenced plants with bacterial and fungal elicitors showed reduced HR which includes stomata closure, NO production and ROS accumulation in guard cells (Pandey et al. 2015; Zhang et al. 2012). Suharsano et al. (2002) reported that rice $\mathrm{d} 1$ mutant which lacks $\mathrm{G} \alpha$ gene showed decreased hypersensitive response to avirulent strains of rice blast. Further 
analysis also reveals that $\mathrm{G}$ protein function in ETItriggered defense response as there was suppression of ROS production and PBZ1 expression by SE in $\mathrm{d} 1$ mutant cell cultures. Heterotrimeric Gproteins are evolutionary novel protein complexes which comprises $\alpha, \beta$ and $\gamma$ subunit present in eukaryotes. These mediate PAMP triggered immunity. Flagelline-sensitive 2 (FLS 2), elongation factor TU (EF-Tu) receptor (EFR) and chitin elicitor reception kinase 1 (CERK1) are well known pathogen-associated molecular pattern (PAMP) receptors belongs to RLK family. In Arabidopsis, treatment with flagelline derived peptide flg 22, EFTu derived peptide elf 18 or chitin trigger the ROS production in WT plants. Mutations in AGB1 leads to reduced ROS production by flg 22 and chitin and complete termination of ROS production by elf 18 which is contrast to GPA1 mutation in which there is no effect on ROS induction by elf 18 , flg 22 or chitin. This suggests that AGB1 and AGG1/2 functions downstream of RLKs, FLS2, EFR and CERK 1 to regulate PAMP oxidative burst (Liu et al. 2013). RLKs functions parallel to GPCRs in plants and $G \beta \gamma$ subunit which functions downstream to RLKs that converges plant defense signaling upon perception of PAMPs. Arabidopsis WT plants possess increased resistance to P.syringae pv. Tomato(P.s.t) DC 3000 when pretreated with flg22, elf18 and chitin induced resistance was more likely reduced in agb1 and agg1, agg2 mutants in contrast to gpa1 mutant plants (Liu et al. 2013). The receptor like cytoplasmic kinase BIK1 also functions downstream to FLS 2, EFR1 and CERK1 that regulates PAMP triggered oxidative burst (Lu et al. 2019; Zhang et al. 2010).

\section{ABBREVIATIONS}

XLG = extra large G- protein, HGPs = Heterotrimeric G- proteins, SAM = Shoot apical meristem, GEF = Guanine nucleotide exchange factor, GPCR= G- protein coupled receptor, RGS = Regulator of $\mathrm{G}$ protein signaling, RLKs = Receptor like kinases, NFR1 = Nod factor receptor1, PLD $\alpha 1=$ Phospholipase D $\alpha 1$, PLC $\beta=$ Phospholipase C, PAMP $=$ Pathogen associated molecular pattern

\section{FUTURE PROSPECTS}

Heterotrimeric $G$ proteins are cytosolic proteins which play vital roles in plant growth. Significant researches and studies have been made regarding function of $G$ proteins, RLKs in plants and mammalian system but several questions still remains unanswered. The pathways of regulation of $\mathrm{G}$ protein mechanism in monocots and eudicots are still not well understood. The mechanism of action of canonical and novel components of $G$ proteins along with regulatory proteins is needed to be explored. Similarly the mechanism of stress tolerance by heterotrimeric $G$ proteins is not clear. Heterotrimeric $G$ proteins signaling is a complex phenomenon and pathways regulating signaling mechanism, activation, role of protein kinases, phosphatases are further needed to be explored. The functions of $G$ proteins subunit possess only handful of information. The role of G $\beta \gamma$ subunit in defense responses is still needed to be understood. Similarly, only few effectors downstream of subunit $\mathrm{G} \alpha$ and XLG has been recognized in plants system. $\mathrm{G}$ proteins have a vital role in nutrient sensing, sugar signaling and controlling plasticity in plants. However, researches have made a significant effort to unravel the mechanism of the same but still more efforts are needed in this direction. Identification of receptors involved in signaling mechanism is one of the major tasks that warrant attention.

\section{REFERENCES}

Apone, F., Alyeshmerni, N., Wiens, K., Chalmers, D., Chrispeels, M.J. and Colucci, G. 2003. The G-proteincoupled receptor GCR1 regulates DNA synthesis through activation of phosphatidylinositol-specific phospholipase C. Plant Physiol., 133: 571-579.

Booker, F.L., Burkey, K.O., Overmyer, K. and Jones, A.M. 2004. Differential responses of $\mathrm{G}$ protein Arabidopsis thaliana mutants to ozone. New Phytol., 162: 633-641.

Booker, F., Burkey, K., Morgan, P., Fiscus, E. and Jones, A. 2012. Minimal influence of G-protein null mutations on ozone-induced changes in gene expression, foliar injury, gas exchange and peroxidase activity in Arabidopsis thaliana L. Plant Cell Environ., 35: 668-681.

Bommert, P., Je, B.I., Goldshmidt, A. and Jackson, D. 2013. The maize Gagene COMPACT PLANT2 functions in CLAVATA signalling to control shoot meristem size. Nature, 502: 555-580.

Botella, J.R. 2012. Can heterotrimeric G proteins help to feed the world? Trends Plant Sci., 17: 563-68.

Chakravorty, D., Trusov, Y., Zhang, W., Acharya, B.R. and Sheahan, M.B. et al. 2011. An atypical heterotrimeric G-protein $\gamma$-subunit is involved in guard cell $\mathrm{K}+$-channel regulation and morphological development in Arabidopsis thaliana. Plant J., 67: 840-51. 
Chakraborty, N., Sharma, P., Kanyuka, K., Pathak, R.R. and Choudhury, D. 2015. Transcriptome analysis of Arabidopsis GCR1 mutant reveals its roles in stress, hormones, secondary metabolism and phosphate starvation. PLoS One, 10: e0117819.

Chakraborty, N., Sharma, P., Kanyuka, K., Pathak, R.R., Choudhury, D., Hooley, R. and Raghuram, N. 2015a. G-protein alpha-subunit (GPA1) regulates stress, nitrate and phosphate response, flavonoid biosynthesis, fruit/ seed development and substantially shares GCR1 regulation in A. thaliana. Plant Mol. Biol., 89: 559-576.

Chakraborty, N., Sharma, P., Kanyuka, K., Pathak, R.R., Choudhury, D., Hooley, R.A. and Raghuram, N. 2015b. Transcriptome analysis of Arabidopsis GCR1 mutant reveals its roles in stress, hormones, secondary metabolism and phosphate starvation. PLoS One, 10: e0117819.

Chakravorty, D. and Assmann, S.M. 2018. G protein subunit phosphorylation as a regulatory mechanism in heterotrimeric $\mathrm{G}$ protein signaling in mammals, yeast, and plants. Biochem. J., 475: 3331-3357.

Chen, J.G., Willard, F.S., Huang, J., Liang, J., Chasse, S.A., Jones, A.M. and Siderovski, D.P. 2003. A seven transmembrane RGS protein that modulates plant cell proliferation. Science, 301: 1728-1731.

Chen, J.G., Ullah, H., Temple, B., Liang, J., Guo, J., Alonso, J.M., Ecker, J.R. and Jones, A.M. 2006. RACK1 mediates multiple hormone responsiveness and developmental processes in Arabidopsis. J. Exp. Bot., 57: 2697-2708.

Colaneri, A.C. and Jones, A.M. 2014. The wiring diagram for plant G signaling. Curr. Opin. Plant Biol., 22: C 56-64.

Delgado-Cerezo, M., Sanchez-Rodriguez, C., Escudero, V., Miedes, E., Fernandez, P.V., Jorda, L., Hernandez-Blanco, C., Sanchez-Vallet, A., Bednarek, P., Schulze-Lefert, P., Somerville, S., Estevez, J.M., Persson, S. and Molina, A. 2012. Arabidopsis heterotrimeric G-protein regulates cell wall defense and resistance to necrotrophic fungi. Mol. Plant, 5: 98-114.

Ding, L., Pandey, S. and Assmann, S.M. 2008. Arabidopsis extralarge $\mathrm{G}$ proteins (XLGs) regulate root morphogenesis. Plant J., 53: 248-63.

Ferrero-Serrano, Á. and Assmann, S.M. 2016. The a-subunit of the rice heterotrimeric $G$ protein, RGA1, regulates drought tolerance during the vegetative phase in the dwarf rice mutant d1. J. Exp. Bot., 67: 3433-3443.

Granier, S. and Kobilka, B. 2012. A new era of GPCR structural and chemical biology. Nat. Chem. Biol., 8: 670-673.

Hackenberg, D., Perroud, P.F., Quatrano, R. and Pandey, S. 2016. Sporophyte formation and life cycle completion in moss requires heterotrimeric G-proteins. Plant Physiol., 172: 1154-1166.

Heo, J.B., Sung, S. and Assmann, S.M. 2012. Ca ${ }^{2+}$-dependent GTPase, extra-large G protein 2 (XLG2), promotes activation of DNA-binding protein related to vernalization 1 (RTV1), leading to activation of floral integrator genes and early flowering in Arabidopsis. J. Biol. Chem., 287: 8242-8253.
Hong, Y. et al. 2016. Plant phospholipases D and C and their diverse functions in stress Responses. Prog. Lipid Res., 62: 55-74.

Huang, J., Taylor, J.P., Chen, J.G., Uhrig, J.F., Schnell, D.J., Nakagawa, T., Korth, K.L. and Jones, A.M. 2006. The plastid protein THYLAKOID FORMATION1 and the plasma membrane G-protein GPA1 interact in a novel sugar-signaling mechanism in Arabidopsis. Plant Cell, 18: 1226-1238.

Joo, J.H., Wang, S., Chen, J.G., Jones, A.M. and Fedoroff, N.V. 2005. Different signaling and cell death roles of Heterotrimeric $G$ protein alpha and beta subunits in the Arabidopsis oxidative stress response to Ozone. Plant Cell, 17: 957-970.

Kansup, J., Tsugama, D., Liu, S. and Takano, T. 2013. The Arabidopsis adaptor protein AP- $3 \mu$ interacts with the G-protein $\beta$ subunit AGB1 and is involved in abscisic acid regulation of germination and post germination development. J. Exp. Bot., 64: 5611-21.

Kumar, S.V., Lucyshyn, D., Jaeger, K.E., Alós, E., Alvey, E., Harberd, N.P. et al. 2012. Transcription factor PIF4 controls the thermosensory activation of flowering. Nature, 484: 242-245.

Lapik, Y.R. and Kaufman, L.S. 2003. The Arabidopsis cupin domain protein AtPirin1 interacts with the G protein $\alpha$-subunit GPA1 and regulates seed germination and early seedling development. Plant Cell, 15: 1578-1590.

Lease, K.A., Wen, J., Li, J., Doke, J.T., Liscum, E. and Walker, J.C. 2001. A mutant Arabidopsis heterotrimeric G protein beta subunit affects leaf, flower, and fruit development. Plant Cell, 13: 2631-2641.

Lee, S., Rojas, C.M., Ishiga, Y., Pandey, S. and Mysore, K.S. 2013. Arabidopsis heterotrimeric G-proteins play a critical role in host and non-host resistance against Pseudomonas syringae pathogens. PLoS One, 8: e82445.

Liang, Y., Gao, Y. and Jones, A.M. 2017. Extralarge G-protein interactome reveals multiple stress response function and partner-dependent XLG subcellular localization. Front. Plant Sci., 8: 1015.

Liu, H.C., Liao, H.T. and Charng, Y.Y. 2011. The role of class A1 heat shock factors (HSFA1s) in response to heat and other stresses in Arabidopsis. Plant Cell Environ., 34: 738-751.

Liu, J., Ding, P., Sun, T., Nitta, Y., Dong, O., Huang, X., Yang, W., Li, X., Botella, J.R. and Zhang, Y. 2013. Heterotrimeric $G$ proteins serve as a converging point in plant defense signaling activated by multiple receptor-like kinases. Plant Physiol., 161: 2146-2158.

Llorente, F., Alonso-Blanco, C., Sanchez-Rodriguez, C., Jorda, L. and Molina, A. 2005. ERECTA receptor-like kinase and heterotrimeric $G$ protein from Arabidopsis are required for resistance to the necrotrophic fungus Plectosphaerella cucumerina. Plant J., 43: 165-180.

Lohani, N., Jain, D., Singh, M.B. and Bhalla, P.L. 2020. Engineering Multiple Abiotic Stress Tolerance in Canola, Brassica napus. Front. Plant Sci., 11(3): 1-26. 
Ludwikow, A. and Sadowski, J. 2008. Gene networks in plant ozone stress response and tolerance. J. Integr. Plant Biol., 50: $1256-1267$.

Lu, D., Wu, S., Gao, X., Zhang, Y., Shan, L. and He, P. 2010. A receptor-like cytoplasmic kinase, BIK1, associates with a flagellin receptor complex to initiate plant innate immunity. PNAS., 107: 486-501.

Ma, Y., Chen, M., Xu, D., Fang, G., Wang, E. and Gao, S. et al. 2015a. G-protein b subunit AGB1 positively regulates salt stress tolerance in Arabidopsis. J. Integr. Agric., 14: 314-325.

Ma, Y., Dai, X., Xu, Y., Luo, W., Zheng, X. and Zeng, D. et al. 2015b. COLD1 confers chilling tolerance in rice. Cell, 160: 1209-1221.

Maruta, N., Trusov, Y., Brenya, E., Parekh, U. and Botella, J.R. 2015. Membrane-localized extra-large G proteins and Gbg of the heterotrimeric $G$ proteins form functional complexes engaged in plant immunity in Arabidopsis. Plant Physiol., 167: 1004-1016.

Misra, S., Wu, Y., Venkataraman, G., Sopory, S.K. and Tuteja, N. 2007. Heterotrimeric G-protein complex and G proteincoupled receptor from a legume (Pisum sativum): role in salinity and heat stress and cross-talk with phospholipase C. Plant J., 51: 656-669.

Mittler, R., Finka, A. and Goloubinoff, P. 2012. How do plants feel the heat? Trends Biochem. Sci., 37: 118-125.

Mudgil, Y., Uhrig, J.F., Zhou, J., Temple, B., Jiang, K. and Jones, A.M. 2009. Arabidopsis N-MYCDOWNREGULATEDLIKE1, a positive regulator of auxin transport in a G protein-mediated pathway. Plant Cell, 21: 3591-609.

Nilson, S.E. and Assmann, S.M. 2010b. The -Subunit of the Arabidopsis heterotrimeric G Protein, GPA1, is a regulator of transpiration efficiency. Plant Physiol., 152: 2067-2077.

O’ Hayre, M., Vázquez-Prado, J., Kufareva, I., Stawiski, E.W., Handel, T.M., Seshagiri, S. and Gutkind, J.S. 2013. The emerging mutational landscape of $G$ proteins and G-protein-coupled receptors in cancer. Nat. Rev. Cancer, 13: $412-424$.

Pandey, S. and Assmann, S.M. 2004. The Arabidopsis putative $\mathrm{G}$ protein-coupled receptor GCR1 interacts with the G protein $\alpha$ subunit GPA1 and regulates abscisic acid signaling. Plant Cell, 16: 1616-1632.

Pandey, S. and Assmann, S.M. 2004. The Arabidopsis putative G protein-coupled receptor GCR1 interacts with the $\mathrm{G}$ protein $\alpha$ subunit GPA1 and regulates abscisic acid signaling. Plant Cell, 16: 1616-32.

Pandey, S. 2016. Phospholipases as GTPase activity accelerating proteins (GAPs) in plants. Plant Signal. Behav., 11: e1176821.

Pandey, S. 2017. Heterotrimeric G-protein regulatory circuits in plants: conserved and novel mechanisms. Plant Signal Behav., 12: e1325983.

Pandey, S. and Vijayakumar, A. 2018. Emerging themes in heterotrimeric G-protein signaling in plants. Plant Sci., 270: 292-300.
Pandey, S. 2019. Heterotrimeric G-Protein Signaling in Plants: Conserved and Novel Mechanisms. Annu. Rev. Plant Biol., 70: 213-38.

Rogato, A., Valkov, V.T., Alves, L.A., Apone, F., Colucci, G. and Chiurazzi, M.2016. Down-regulated Lotus Japonicus GCR1 Plants Exhibit Nodulation Signalling Pathways Alteration. Plant Sci., 247: 71-82.

Ross, E.M. 2008. Coordinating speed and amplitude in G-protein signaling. Curr. Biol., 18: R777-R783.

Ross, E.M. 2011. G alpha (q) and phospholipase C-beta: turn on, turn off, and do it fast. Sci Signal, 4: pe5.

Roy Choudhury, S., Riesselman, A.J. and Pandey, S. 2014. Constitutive or seed specific overexpression of Arabidopsis G-protein g subunit 3 (AGG3) results in increased seed and oil production and improved stress tolerance in Camelina sativa. Plant Biotechnol. J., 12: 49-59.

Roy Choudhury, S. and Pandey, S. 2015. Phosphorylationdependent regulation of G-protein cycle during nodule formation in soybean. Plant Cell, 27: 3260-76.

Roy Choudhury, S. and Pandey, S. 2016. Interaction of heterotrimeric G-protein components with receptor like kinases in plants: an alternative to the established signaling paradigm? Mol. Plant, 9: 1093-95.

Roy Choudhury, S. and Pandey, S. 2016. The role of PLD $\alpha 1$ in providing specificity to signal-response coupling by heterotrimeric G-protein components in Arabidopsis. Plant J., 86: 50-61.

Roy Choudhury, S., Marlin, M.A. and Pandey, S. 2019. The role of $\mathrm{G} \beta$ protein in controlling cell expansion via potential interaction with lipid metabolic pathways. Plant Physiol., 179: 1159-1175.

Scherm, H. and Coakley, S.M. 2003. Plant pathogens in a changing world. Australas. Plant Pathol., 32: 157-165.

Siderovski, D.P. and Willard, F.S. 2005. The GAPs, GEFs, and GDIs of heterotrimeric G-protein $\alpha$ subunits. Int. J. Biol. Sci., 1: 51-66.

Stateczny, D., Oppenheimer, J. and Bommert, P. 2016. G protein signaling in plants: minus times minus equals plus. Curr. Opin. Plant Biol., 34: 127-135.

Stewart, A. and Fisher, R.A. 2015. Introduction G proteincoupled receptors and RGS proteins. Prog. Mol. Biol. Transl. Sci., 133: 1-11.

Subramaniam, G., Trusov, Y., Lopez-Encina, C., Hayashi, S., Batley, J. and Botella, J.R. 2016. Type B heterotrimeric G protein $\gamma$-subunit regulates auxin and ABA signaling in tomato. Plant Physiol., 170: 1117-34.

Suharsono, U., Fujisawa, Y., Kawasaki, T., Iwasaki, Y., Satoh, H. and Shimamoto, K. 2002. The heterotrimeric G protein alpha subunit acts upstream of the small GTPase Rac in disease resistance of rice. Proc. Natl. Acad. Sci. U.S.A., 99: 13307-13312.

Sun, H., Qian, Q., Wu, K., Luo, J. and Wang, S. 2014. Heterotrimeric $G$ proteins regulate nitrogen-use efficiency in rice. Nat. Genet., 46: 652-56. 
Sun, S., Wang, L., Mao, H., Shao, L. and Li, X. 2018. A G-protein pathway determines grain size in rice. Nat. Commun., 9: 851.

Swain, D.M., Sahoo, R.K., Srivastava, V.K., Tripathy, B.C., Tuteja, R. and Tuteja, N. 2017. Function of heterotrimeric G-protein $g$ subunit RGG1 in providing salinity stress tolerance in rice by elevating detoxification of ROS. Planta., 245: 367-383.10.

Thathiah, A. and De Strooper, B. 2011. The role of G proteincoupled receptors in the pathology of Alzheimer's disease. Nat. Rev. Neurosci., 12: 73-87.

Thung, L., Chakravorty, D., Trusov, Y., Jones, A.M. and Botella, J.R. 2013. Signaling specificity provided by the Arabidopsis thaliana heterotrimeric G-protein g subunits AGG1 and AGG2 is partially but not exclusively provided through transcriptional regulation. PLoS One, 8: e58503.

Torres, M.A., Morales, J., Sanchez-Rodriguez, C., Molina, A. and Dangl, J.L. 2013. Functional interplay between Arabidopsis NADPH oxidases and heterotrimeric G protein. Mol. Plant Microbe. Interact., 26: 686-694.

Trusov, Y., Rookes, J.E., Chakravorty, D., Armour, D., Schenk, P.M. and Botella, J.R. 2006. Heterotrimeric G proteins facilitate Arabidopsis resistance to necrotrophic pathogens and are involved in jasmonate signaling. Plant Physiol., 140: 210-220.

Trusov, Y., Sewelam, N., Rookes, J.E., Kunkel, M., Nowak, E., Schenk, P.M. and Botella, J.R. 2009. Heterotrimeric G proteins-mediated resistance to necrotrophic pathogens includes mechanisms independent of salicylic acid-, jasmonic acid/ethylene- and abscisic acid-mediated defense signaling. Plant J., 58: 69-81.

Tuteja, N. and Sopory, S.K. 2008. Plant signaling in stress: G-protein coupled receptors, heterotrimeric G-proteins and signal coupling via phospholipases. Plant Signal Behav., 3: 79-86.

Ullah, H., Chen, J.G., Wang, S. and Jones, A.M. 2002. Role of a heterotrimeric $G$ protein in regulation of Arabidopsis seed germination. Plant Physiol., 129: 897-907.

Urano, D., Jones, J.C., Wang, H., Matthews, M., Bradford, W., Bennetzen, J.L. and Jones, A.M. 2012a. G protein activation without a GEF in the plant kingdom. PLoS Genet., 8: e1002756.

Urano, D., Phan, N., Jones, J.C., Yang, J., Huang, J., Grigston, J., Taylor, J.P. and Jones, A.M. 2012b. Endocytosis of the seven-transmembrane RGS1 protein activates G-proteincoupled signalling in Arabidopsis. Nat. Cell. Biol., 14: 1079-1088.

Urano, D., Chen, J.G., Botella, J.R. and Jones, A.M. 2013. Heterotrimeric $G$ protein signalling in the plant kingdom. Open Biol., 3: 120186.

Urano, D. and Jones, A.M. 2014. Heterotrimeric G proteincoupled signaling in plants. Annu. Rev. Plant Biol., 65: 365-84.

Urano, D., Maruta, N., Trusov, Y., Stoian, R., Wu, Q., Liang, Y., Jaiswal, D.K., Thung, L., Jackson, D., Botella, J.R. and Jones, A.M. 2016a. Saltational evolution of the heterotrimeric $G$ protein signaling mechanisms in the plant kingdom. Sci. Signal, 9: ra93.

Warpeha, K.M., Lateef, S.S., Lapik, Y., Anderson, M., Lee, B.S. and Kaufman, L.S. 2006. G-protein-coupled receptor 1, G-protein $\alpha$-subunit 1, and prephenate dehydratase 1 are required for blue light-induced production of phenylalanine in etiolated Arabidopsis. Plant Physiol., 140: 844-855.

Wendt, T., Holme, I., Dockter, C., Preuss, A. and Thomas, W. 2016. HvDep1 is a positive regulator of culm elongation and grain size in barley and impacts yield in an environment-dependent manner. PLoS One, 11: e0168924.

Wu, Q., Regan, M., Furukawa, H. and Jackson, D. 2018. Role of heterotrimeric Gaproteins in maize development and enhancement of agronomic traits. PLoS Genet., 14: e1007374.

Wu, Q., Xu, F. and Jackson, D. 2018. All together now, a magical mystery tour of the maize shoot meristem. Curr. Opin. Plant Biol., 45: 26-35.

Wu, T.Y. and Urano, D. 2018. Genetic and Systematic Approaches Toward G Protein-Coupled Abiotic Stress Signaling in Plants Ting-Ying. Front. Plant Sci., 9: 1378.

Xu, D.B., Chen, M., Ma, Y.N., Xu, Z.S., Li, L.C., Chen, Y.F. and Ma, Y.Z. 2015. A G-protein beta subunit, AGB1, negatively regulates the $\mathrm{ABA}$ response and drought tolerance by down-regulating AtMPK6-related pathway in Arabidopsis. PLoS One, 10: e0116385.

Yu, Y. and Assmann, S.M. 2015. The heterotrimeric G-protein b subunit, AGB1, plays multiple roles in the Arabidopsis salinity response. Plant Cell Environ., 38: 2143-2156.

Zhang, L., Hu, G., Cheng, Y. and Huang, J. 2008. Heterotrimeric $\mathrm{G}$ protein alpha and beta subunits antagonistically modulate stomatal density in Arabidopsis thaliana. Dev. Biol., 324: 68-75.

Zhang, H., Wang, M., Wang, W., Li, D., Huang, Q., Wang, Y., Zheng, X. and Zhang, Z. 2012. Silencing of G proteins uncovers diversified plant responses when challenged by three elicitors in Nicotiana benthamiana. Plant Cell Environ., 35: $72-85$.

Zhang, D.P., Zhou, Y., Yin, J.F., Yan, X.J., Lin, S. and Xu, W.F. et al. 2015. Rice G protein subunits qPE9-1 and RGB1 play distinct roles in abscisic acid responses and drought adaptation. J. Exp. Bot., 66: 6371-6384.

Zhang, T., Xu, P., Wang, W., Wang, S. and Caruana, J.C. 2017. Arabidopsis G-protein $\beta$ subunit AGB1 interacts with BES1 to regulate brassinosteroid signaling and cell elongation. Front Plant Sci., 8: 2225.

Zhao, J. and Wang, X. 2013. Biochemical analysis of the interaction between phospholipase D alpha1 and GTPbinding protein alpha-subunit from Arabidopsis thaliana. Methods Mol. Biol., 1043: 21-35.

Zhu, H., Li, G.J., Ding, L., Cui, X., Berg, H., Assmann, S.M. and Xia, Y. 2009. Arabidopsis extra large G-protein 2 (XLG2) interacts with the $G$ beta subunit of heterotrimeric $G$ protein and functions in disease resistance. Mol. Plant, 2: 513-525. 
